\title{
Correspondence
}

\section{WILLIAM STRATHEARN KEITH (1902-1987)}

\section{To the Editor:}

Dr. Ross Fleming, in the obituary published in the Canadian Journal of Neurological Sciences of May 1988, has so well portrayed the truly remarkable man that Bill Keith was. Many cherish fond memories of Bill, and are indebted to Dr. Fleming for what he has written.

This letter is to tell of Bill Keith's activity outside Canada in helping the development of neurosurgical services in Jamaica. In the early 60 's, the staff of the Hospital for Sick Children was specially interested in pediatrics on the island of Jamaica. At the instigation of Dr. J.S. Pritchard in 1964 Bill, accompanied by his wife Eleanor, paid the first of many visits to Jamaica to assist me in the establishment of neurosurgical services there.

During the next ten years Bill, often with John Silversides, would spend a month working at the University Hospital of the West Indies in Kingston. The qualities so well recorded by Dr. Ross Fleming, endeared him to us, and a visit from Bill was always a special event. His help, reassurance, and encouragement did much to foster the development of neurosurgery in Jamaica.

He befriended many medical graduates of the University of the West Indies who came to Canada for further study in various specialties.

Thank you for the opportunity to place on record Bill Keith's contribution in Jamaica.

\section{Andrew Masson, University of Alberta Hospitals, Edmonton (Formerly Professor of Neurosurgery, University of the West Indies, Jamaica)}

\section{ELEVATED SPINAL FLUID PRESSURE AS ONLY SIGN OF CEREBRAL VENOUS THROMBOSIS}

\section{To the Editor:}

Cerebral venous thrombosis (CVT) is often overlooked clinically. ${ }^{1}$ The initial symptoms, e.g. headache, nausea or fever are non-specific and later in the course a broad spectrum of clinical manifestations may develop. ${ }^{2}$ As a result, CVT can mimic several conditions, thereby often hampering a proper diagnosis. We report the history of a patient in whom elevated spinal fluid pressure (SFP) was the vital clue to considering, and later diagnosing CVT.

\section{CASE REPORT}

Four weeks prior to admission this 20-year-old woman developed mucopurulent rhinorrhea, a sore throat, and dysphagia. Two weeks later she experienced bilateral frontal throbbing headache. One day prior to admission she developed nausea, fever and a stiff and painful neck. She had been taking an oral contraceptive containing norgestriol and ethynilestradiol and was smoking 20 cigarettes a day.

On admission, her temperature was $40.1^{\circ} \mathrm{C}$, pulse-rate 114 and blood pressure $110 / 70 \mathrm{mmHg}$. General physical examination disclosed neck movements to be stiff and painful in all directions. Otherwise there were no abnormalities. The neurological examination including fundoscopy was unremarkable. X-rays of paranasal sinuses were normal. The ESR was $37 \mathrm{~mm}$, WBC was $13,6.10^{9} / 1$ with a normal differentiation. Hematocrit and platelet count were normal. Lumbar puncture on two occasions yielded clear cerebrospinal fluid, both times with an opening pressure of $260 \mathrm{~mm} \mathrm{H} \mathrm{H}_{2} \mathrm{O}$, the constitution being normal. CT of the brain revealed no abnormalities.

During the next few days her headache increased. Neurological and fundoscopic examination remained unremarkable. On the seventh day, on the basis of the elevated SFP and the progression of her complaints, angiography was performed, which revealed an occlusion of the anterior part of the superior sagittal sinus. Coagulation tests all were normal. Oral contraceptive was withdrawn and she was treated with coumarin for six months. Five months after the beginning of her complaints angiography was repeated and showed no abnormalities. Repeated LP revealed a SFP of $215 \mathrm{~mm} \mathrm{H} \mathrm{H}_{2} \mathrm{O}$, and the patient was asymptomatic.

The finding of elevated SFP is unspecific, as either tumorous or non-tumorous causes can lead to this sign. However, when CT and CSF constitution are normal, there are only a limited number of possible causes, including benign intracranial hypertension and CVT. ${ }^{3}$ The patient presented here had the clinical picture of meningitis. However, CSF constitution was normal and elevated SFP was the only abnormal finding, finally leading to the diagnosis CVT.

We would like to point out the importance of measuring SFP in all patients with acute or subacute brain-syndromes, even in the absence of papilledema and CT-abnormalities. Consequently, the present trend among clinicians to neglect measuring SFP should be looked at critically.

\author{
Bob J. van Hilten, \\ Joost Haan, \\ Axel $R$. Wintzen, \\ Department of Neurology, \\ University Hospital Leiden, \\ The Netherlands
}

1. Averback P. Primary cerebral venous thrombosis in young adults: The diverse manifestations of an under-recognized disease. Ann Neurol 1979; 3: 81-86.

2. Bousser MG, Chiras J, Bories J, Castaigne P. Cerebral venous thrombosis - A review of 38 cases. Stroke 1985; 16: 199-213.

3. Corbett JJ. Problems in the diagnosis and treatment of pseudotumour cerebri. Can J Neurol Sci 1983; 10: 221-229.

\section{LYMPHOCYTIC ADENOHYPOPHYSITIS IN A MAN}

\section{To the Editor:}

Recently, McDermott and colleagues ${ }^{1}$ reported two additional cases of lymphocytic adenohypophysitis in women. Their 